\title{
Moringa oleifera restored semen quality, hormonal profile, and testicular morphology against Highly Active Antiretroviral Therapy- induced toxicity in adult male Wistar rats
}

\author{
B. Ogunlade ${ }^{1}$, S. O. Jeje ${ }^{2}$, S. A. Adelakun ${ }^{1}$, G.T. Akingbade ${ }^{1}$ \\ ${ }^{1}$ Human Anatomy Department, Federal University of Technology Akure, Ondo State, Nigeria \\ ${ }^{2}$ Physiology Department, Federal University of Technology Akure, Ondo State, Nigeria
}

\begin{abstract}
Objective: Reproductive toxicity has been greatly linked with Highly Active Antiretroviral Therapy (HAART) use. This study investigated the effects of Moringa oleifera Leaf Extract (MOE) on HAART-induced testicular toxicity in adult male Wistar rats.

Methods: Twenty adult male Wistar rats (150-200 g) were assigned into four groups $(n=5)$. Group A received distilled water; Group B received (orally) $200 \mathrm{mg} / \mathrm{kg}$ BW HAART only; Group C received (orally) $200 \mathrm{mg} / \mathrm{kg}$ BW HAART and $100 \mathrm{mg} / \mathrm{kg}$ BW MOE (low dose group) and Group D received (orally) $200 \mathrm{mg} / \mathrm{kg}$ BW HAART and 300 $\mathrm{mg} / \mathrm{kg}$ BW MOE. At the end of the 28-day experiment, body and testicular weights were measured; serum and testis obtained were subjected to hormone profiling, biochemical and histological studies.

Results: HAART caused a significant decrease in body and testicular weight, testicular distortion and spermatogenic cell disorganization, altered semen quality and function, hormonal profiles, and oxidative stress markers (SOD, CAT, GSH) were significantly decreased with the concurrent increase in MDA level. However, treatment with MOE improved sperm parameters, testis morphology, antioxidants markers, and hormones assessments.

Conclusions: The exposure to HAART produced marked testicular toxicity, ameliorated using Moringa oleifera leaf extract, thereby preserving testicular physiological function and morphology.
\end{abstract}

Keywords: HAART, Moringa oleifera, infertility, sperm parameters, oxidative stress

\section{INTRODUCTION}

Highly Active Antiretroviral Therapy (HAART) is an active combination regimen capable of relegating Human Immunodeficiency Virus (HIV) to the history books (Granich et al. 2010). With the advent of combination regimen (combination antiretroviral therapy - cART), HIV control is reduced via several conditions such as treatment compliance, the toxicity of the drug, and bioavailability (Meynard et al., 2011). There were reductions in the morbidity and mortality rates of associated HIV-infections after the introduction of the HAART regimen in 1996 (Reginald et al., 2011). The consumption of potent CART caused the reconstitution of the immune system, thereby increasing life expectancy and drastically decreasing opportunistic infections (Pineda et al., 2011). However, recent observation of patients discontinuing therapy and relative withdrawal due to significant adverse reactions has prompt researchers to address the treatment failures (Carr \& Cooper, 2000). Most clinically reported complications of HAART usage includes AIDS-related insulin resistance, hyperglycemia, gastrointestinal, and lipodystrophy symptoms experienced by several patients (Hagmann, 2003; Montessori et al., 2004).
Reproductive organ toxicity associated with HAART usage is increasing globally, especially testicular damage due to differential sensitivity to either the germ or somatic cells and their response to the toxicant (Creasy, 2001; Kushnir \& Lewis, 2011). Several manifestations of chemical toxicants have resulted in testicular atrophy with germ cell loss, multinucleated gonocytes, Sertoli cells vacuolization, Leydig cell apoptosis/hyperplasia and ultimately resulting in infertility (Kushnir \& Lewis, 2011; Adegoke, 2015). The effects of HAART on a male subject by clinicians are minimal, though studies have substantiated altered sperm qualities among men using the HAART regimen (Bujan et al., 2007).

The exponential increase of medicinal plant use has increased globally over the past decades, despite much unproven scientific validation (Azu et al., 2016). Nearly 21,000 medicinal plants are used globally on different continents (Azu et al., 2016). The most common usage of medicinal plants is against numerous non-communicable diseases like diabetes mellitus as well as infectious diseases like HIV/AIDs (Azu et al., 2016). The originality, relative accessibility, and minimal side effects have increased the use of indigenous plants in recent years, to address the most common ailments around the globe (Mishra et al., 2011). Herbal drugs of medicinal value are now commonly accessible commercially, particularly in developed countries; thereby potentiating their significance in fighting several diseases (Mishra et al., 2011). Moringa oleifera, belonging to the family Moringaceae, commonly known as Horseradish in English (Nadkarni, 2009) is one of the best known distributed and naturalized species of the family (Anwar et al., 2007). It is cultivated worldwide (mostly in Asia and Africa), especially in gardens and in house yards, thriving best in rainy or wet weather, and is numerous near the sandy beds of rivers and streams (Anwar et al., 2007). Phytochemical constituents of Moringa oleifera leaf extract (MOE) contains specific plant pigments with powerful anti-oxidative potential such as vitamins C, E, A, carotenoids - lutein, kaempferol, quercetin, rutin (Siddhuraju \& Becker, 2003; Aslam et al., 2005). Furthermore, the flavonoids present in $\mathrm{MOE}$, such as quercetin and phenolics are responsible for the scavenging of Reactive Oxygen Species (ROS) released from mitochondria, which in turns serve to protect the cells against the deleterious effects of oxidative stress (Kamalakkannan \& Prince, 2006; Al-Malki \& El Rabey, 2015). In addition, phytochemical constituents of the leaves extracts such as glucosinolates, niazimicin, and benzyl isothiocyanate were reported to be responsible for the anticancer potential of MOE (Nakamura et al., 2002; Hermawan et al., 2012).

MOE has been reported in curing several ailments such as skin infections, asthma, bronchitis, catarrh, and inflammation of the lungs (Mahmood et al., 2010; Hamza, 2010; Singh \& Sharma, 2012). In addition, MOE acts against inflammation, hypertension, tumors, free radicals, ulcer, epilepsy, and diabetes (Lai et al., 2010; Paliwal et al., 2011; 
Sharma et al., 2012; Huang et al., 2012). The response from Moringa oleifera leave extracts on HAART-induced alteration in sperm characterization, hormone assessment, antioxidant parameters, and testicular morphology in adult male Wistar rats is investigated.

\section{MATERIALS AND METHODS}

\section{Chemical}

Zidovudine (AZT) $300 \mathrm{mg}$, Nevirapine (NVP) $200 \mathrm{mg}$, Lamivudine (3TC) $150 \mathrm{mg}$ (HAART combination therapy) produced by Mylan laboratories Limited, Maharashtra, India was purchased from a commercial source at Matador pharmacy Limited, Akure, Ondo State, Nigeria, from the National Agency for Food Drug Administration and Control (NAFDAC) Reg. NO.: A4-2813 and CAT No: 3061315.

\section{Plant collection, identification, and Extract prepa- ration}

Moringa Oleifera's fresh leaves were collected from the Research Farm - Federal University of Technology, Akure, Nigeria, and were identified and authenticated in the herbarium section of the Centre for Research and Development (CERAD) of the Federal University of Technology, Akure, Nigeria. FUTA0190 voucher deposited for reference purposes. The leaves were thoroughly washed and oven-dried at $37^{\circ} \mathrm{C}$ for $48 \mathrm{~h}$ and pulverized into a smooth powder.

The pulverized sample $(850 \mathrm{~g})$ was suspended in 1000 $\mathrm{ml}$ of distilled water with regular stirring for $72 \mathrm{hrs}$. The solution obtained was filtered and the resulting filtrate was concentrated in a water bath $\left(40^{\circ} \mathrm{C}\right)$ and yielded $463.21 \mathrm{~g}$ of crude extract, corresponding to $58.12 \%$ of the residue. The crude extract from Moringa Oleifera was kept airtight and refrigerated before use.

\section{Animals}

A total of 20 adult male Wistar rats weighing 150-200 g (aged 8-10 weeks) were obtained from the breeding stock, at the Federal University of Technology, Akure. The rats were collected in isolated cages and acclimatized for 7 days in the experimental house of the Department of Human Anatomy, Federal University of Technology, Akure before the commencement of the experiment. They were maintained with a constant $12 \mathrm{~h} / 12 \mathrm{~h}$ dark and light cycle. The Ethics Committee of the Federal University of Technology, Akure (HREC/07/19/120), approved all animal handling procedures.

\section{Study design}

The rats were divided into four groups $(n=5)$, labeled as groups A, B, C, and D. The HAART (Chris-Ozoko et al., 2013) and MOE dosages (Villarruel-López et al., 2018) were prepared and administered once daily to the animals. Group A received water. Group B received $200 \mathrm{mg} / \mathrm{kg}$ BW HAART (orally) only; Group C received with $200 \mathrm{mg} / \mathrm{kg}$ BW HAART (orally) and a low dose of $100 \mathrm{mg} / \mathrm{kg} \mathrm{BW} \mathrm{MOE} \mathrm{and}$ Group D received $200 \mathrm{mg} / \mathrm{kg}$ BW HAART (orally) (in $2.3 \mathrm{ml}$ of distilled water) and a high dose of $300 \mathrm{mg} / \mathrm{kg}$ BW MOE only (in $2.3 \mathrm{ml}$ of distilled water). The experiment lasted for 28 days, after which the animals were slaughtered.

The animals were observed for abnormalities and illnesses. The experimental procedures followed the provided recommendations in the "Guide for the Care and Use of Laboratory Animals" prepared by the National Academy of Sciences. The rats were fed with standard rat chow and water ad libitum. The weights of the animals were recorded upon procurement, during acclimatization, at the commencement of the experiment, and weekly throughout the experimental period.

\section{Surgical procedure}

After the completion of the experiment, the animals were administered intraperitoneal pentobarbital sodium $(40 \mathrm{mg} / \mathrm{kg}$ ) and their abdominal regions were dissected and the testes of all the animals were immediately extracted. We collected the serum from the blood samples after centrifuging for analysis. The testicular weights were measured and they were fixed in Bouin's fluid for histological analysis.

\section{Sperm collection and analyses}

The cauda epididymis tissue taken from each animal for sperm analysis was placed in $2 \mathrm{ml}$ of $37^{\circ} \mathrm{C}$ salines. The tissue was then crushed by making small incisions and the spermatozoon was dispersed in the saline solution. Sperm count was performed using the Makler counting chamber. Approximately $10 \mu$ l of sperm suspension samples were taken and evaluated under a light microscope with $10 \times$ magnification. The sperm parameters were determined using standard protocols.

\section{Sperm morphology}

This was carried out as described by Saalu et al. (2013). The sperm morphology was evaluated with the aid of a light microscope at $\times 400$ magnification. The caudal sperm was taken from the original dilution for motility and diluted 1:20 with 10\% neutral buffered formalin (Sigma-Aldrich, Canada). We categorized the spermatozoa in wet preparations using phase contrast optics. In this study, a spermatozoon was considered morphologically abnormal if it had a rudimentary tail, round or detached head, and was expressed as a percentage of morphologically normal sperm.

\section{Biochemical Analysis}

The level of lipid peroxidation products was estimated following the method published by Niehaus \& Samuelsson (1968). Non-enzymatic antioxidants such as reduced glutathione (GSH) and catalase (CAT) were estimated as described by Ellman (1959) and Sinha (1972), respectively. We determined the SOD activity in the testes according to the method described by Marklund \& Marklund (1974).

\section{Hormone Assessment}

Testosterone (TT), Follicle-stimulating hormone (FSH), and Luteinizing hormone (LH) were determined using an immunoassay (ELISA), according to manufacturer instructions.

\section{Testes Histomorphology}

The testes fixed in Bouin's fluid for $24 \mathrm{hr}$ and underwent tissue processing technique procedures as described by Adelakun et al. (2019); thereafter stained with Hematoxylin and Eosin, and photomicrographs were taken at a magnification of $100 x$ on a Leica DM750 microscope.

\section{Data presentation and statistical analysis}

We analyzed the data statistically with one-way ANOVA, followed by Dunnett's comparison test using GraphPad Prism 5 Windows (GraphPad Software, San Diego, California, USA). Values expressed as Mean \pm SEM. The level of significance was $p<0.05$.

\section{RESULTS \\ Body and testicular weights}

Effects of MOLE on the body and testicular weights on normal and HAART-treated rats

The result revealed that rats treated with HAART showed a significant decrease in body and testicular weights relative to control animals $(p<0.05)$ (Figs. 1 and 2$)$. 


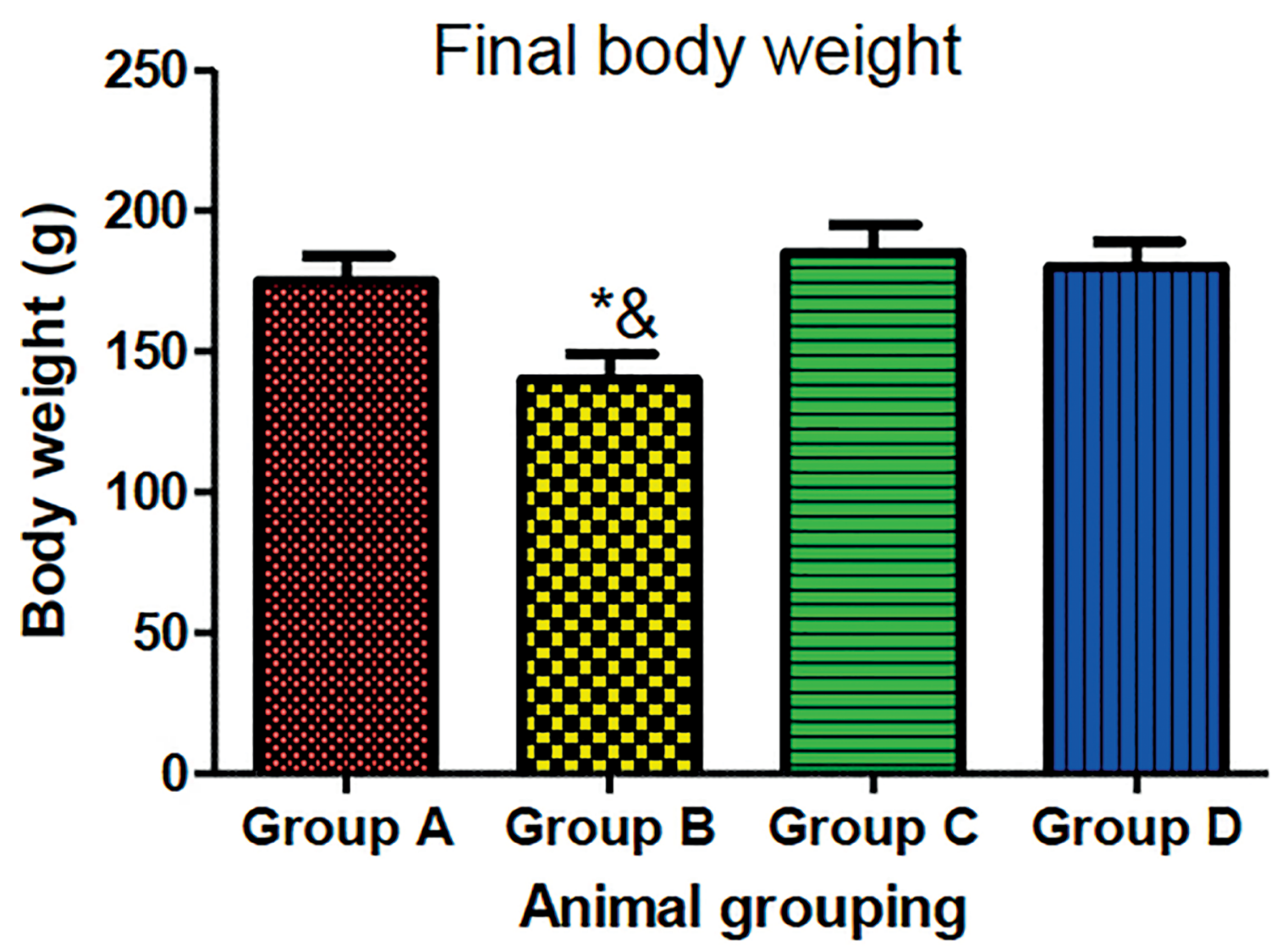

Figure 1. Effect of MOE on body weight on HAART-induced normal and experimental rats. $* p<0.05$ as compared to group $\mathrm{A}$; \& $p<0.05$ as compared to groups $\mathrm{C}$ and $\mathrm{D}$.

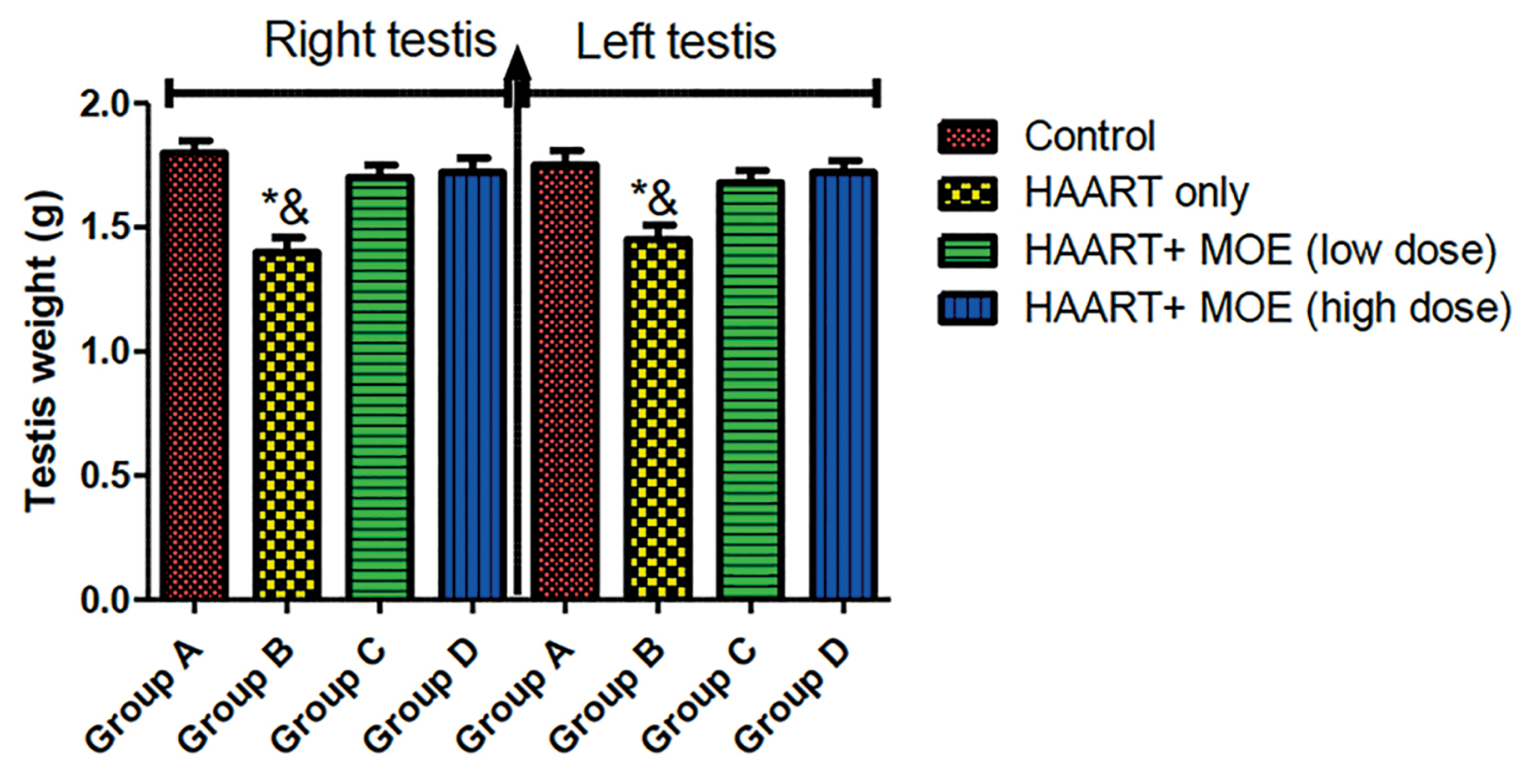

Animal grouping

Figure 2. Effect of MOE on testes weight (right and left) on HAART-induced normal and experimental rats. $* p<0.05$ as compared to group A; \& $p<0.05$ as compared to groups $\mathrm{C}$ and $\mathrm{D}$.

However, the rats administered with both HAART and MOLE in high and low doses showed a significant increase in their final body weight and testicular weight relative to the HAART-only group $(p<0.05)$ (Figs. 1 and 2$)$. 
Semen characterization

Effects of MOE on sperm morphology (neck, tail, and head defects and normal) on normal and HAART-treated rats

The results revealed that rats treated with HAART only showed a significant decrease $(p<0.05)$ in morphology (normal) with a concomitant increase in neck, tail, and head defects, relative to the controls (Fig. 3). However, the rats administered with both HAART and MOE in high and low doses had a significant increase in morphology (normal), with a concomitant decrease in neck, tail, and head defects when compared with the HAART-only group $(p<0.05$; Fig. 3).

Furthermore, the results showed that rats treated with HAART-only showed a significant decrease $(p<0.05)$ in progressive assessment (fast), volume, motile count, percentage motility, total count, and viability with a concomitant increase in progressive assessment (slow), relative to the control animals (Fig. 4). However, the rats administered with both HAART and MOE in high and low doses had a significant increase in progressive assessment (fast), volume, motile count, percentage motility, total count, and viability with a concomitant decrease in progressive assessment (slow) relative to the HAART-only group $(p<0.05)$ (Fig 4$)$.

\section{Biochemical assay}

Effects of MOE on MDA, GSH, SOD, and CAT level on HAART-treated and normal rats

The results showed that rats treated with HAART only showed a significant decrease in GSH, SOD, and CAT activities (Fig. 5) with a corresponding increase in MDA relative to the control animals ( $p<0.05$; Fig. 5$)$. However, the rats administered with both MOE and HAART in high and low doses showed a significant increase in GSH, SOD and, CAT activities (Fig. 5) with the corresponding decrease in MDA relative to the HAART-only group, (Fig. 5) except in MDA, which showed a significant decrease $(p<0.05$; Fig. 5). Although, there was a significant decrease in GSH, SOD, and CAT activities when the rats administered both MOE and HAART in high and low doses relative to the control, (Fig. 5) except in MDA, which shows a significant increase $(p<0.05$; Fig. 5).

\section{Hormonal assay}

Effects of MOE on serum level of FSH, LH, and TT on HAART-treated and normal rats

The results revealed that rats treated with HAART only showed a significant decrease in $\mathrm{FSH}, \mathrm{LH}$, and $\Pi \mathrm{T}$ activities relative to the control animals ( $p<0.05$; Fig. 6$)$. However, the rats administered with both MOE and HAART in high and low doses showed a significant increase in $\mathrm{FSH}, \mathrm{LH}$, and $T$ activities relative to the HAART-only group $(p<0.05$; Fig. 6). Although, there was a significant decrease in $\mathrm{FSH}$, $\mathrm{LH}$, and $\mathrm{TT}$ activities when the rats administered both MOE and HAART in high and low doses relative to the control animals $(p<0.05$; Fig. 6$)$.

\section{Histological evaluations}

The testicular histoarchitecture of the HAART-only group (B) showed distortions in the tubular structure and disorganization of the Sertoli cells within the seminiferous tubules, hypocellularity of spermatogonia, disruption
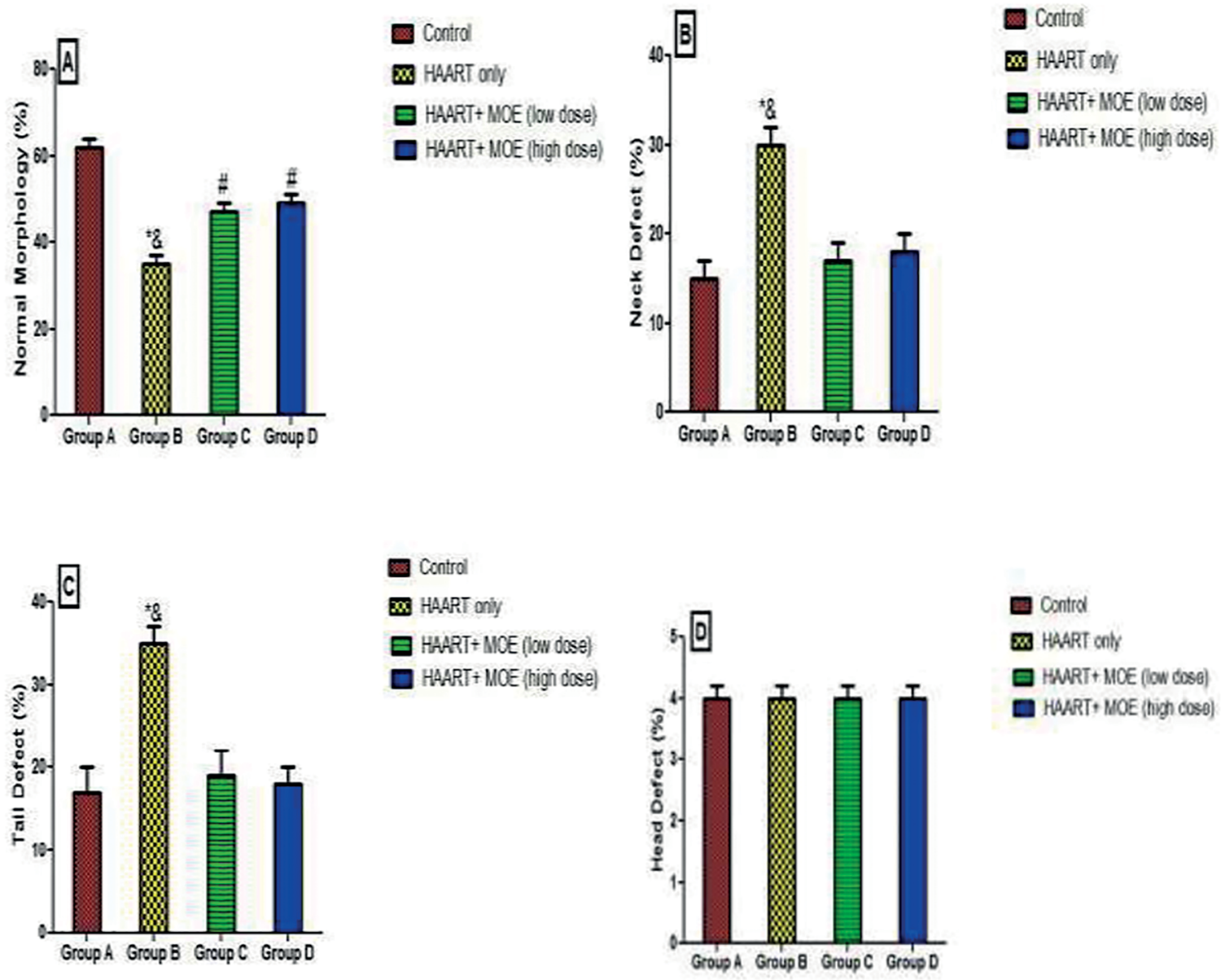

Figure 3. Effect of MOE on sperm morphology (Neck, Tail, and Head defects and Normal) on HAART-induced normal and experimental rats. $* p<0.05$ as compared to group $A ; \& p<0.05$ as compared to groups $C$ and $D$. 


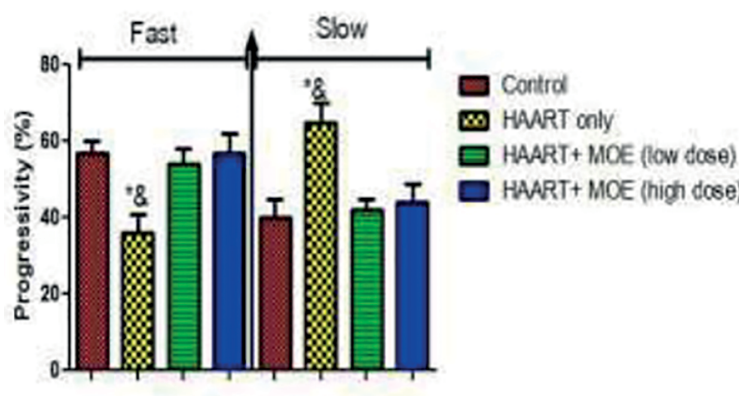

Animal grouping

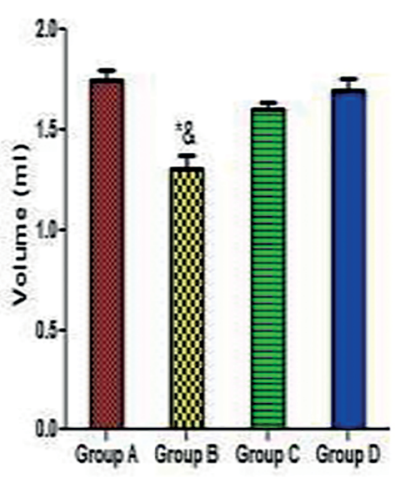

Cortrd

W HART orly

HAART + WOE (low dose)

HAART + MOE (high dose)

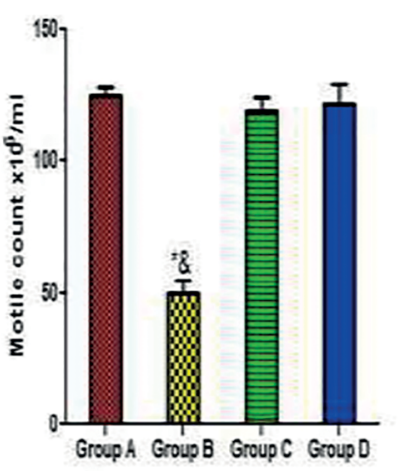

Confol

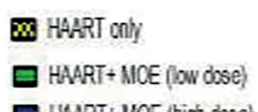

HAART + NOE (high dose)

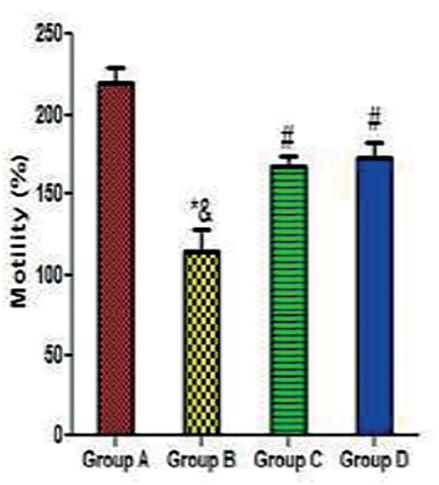

Control

M HAART only

HAART + MOE (low dose)

HAART+ MOE (high dose)
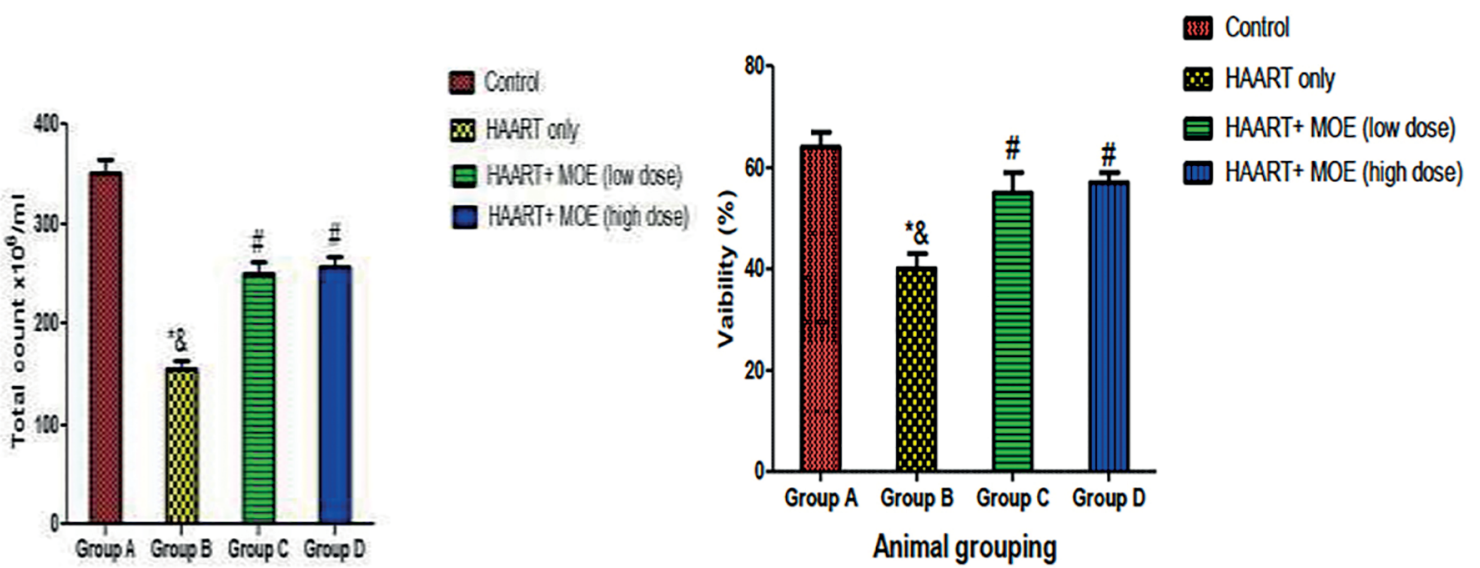

Figure 4. Effect of MOE on Progressive assessment (fast and slow) on HAART-induced normal and experimental rats. ${ }^{*} p<0.05$ as compared to group $\mathrm{A} ; \& p<0.05$ as compared to groups $\mathrm{C}$ and $\mathrm{D}$.

of spermatogenesis, empty lumen, decrease in germinal epithelium thickness, and reduction in the diameter of the seminiferous tubules when compared with the controls (Group A; Fig. 7). In addition, HAART distorted the seminiferous tubules with loss of normal distribution of epithelial lining and vacuolar cytoplasm compared with the controls (Group A). However, testicular photomicrograph of the control group had similar characteristics with the high and low dose MOE rats (groups $C$ and D), showing oval or circular presentation with distinctive stratified seminiferous epithelium with lumens possessing spermatogenic cells and prominent Leydig cells (Fig. 7). The testicular section of the rats (groups $C$ and D) administered with both MOE and HAART at high and low doses, respectively, showed restored microarchitecture of the testicular morphology with mild distortion of the tubular architecture and disorganization of the spermatogenic cells in the seminiferous tubules (Fig. 7).

\section{DISCUSSION}

In this study, the combination HAART therapy (Zidovudine, Lamivudine, and Nevirapine) causes significant changes in the body and testicular weights. Previous observations showed that spermatogenesis is capable of causing declines in testicular structures, which is evident in our study. Additionally, the weight coefficient (testicular and body weight ratio) is an important sensitive and effective 

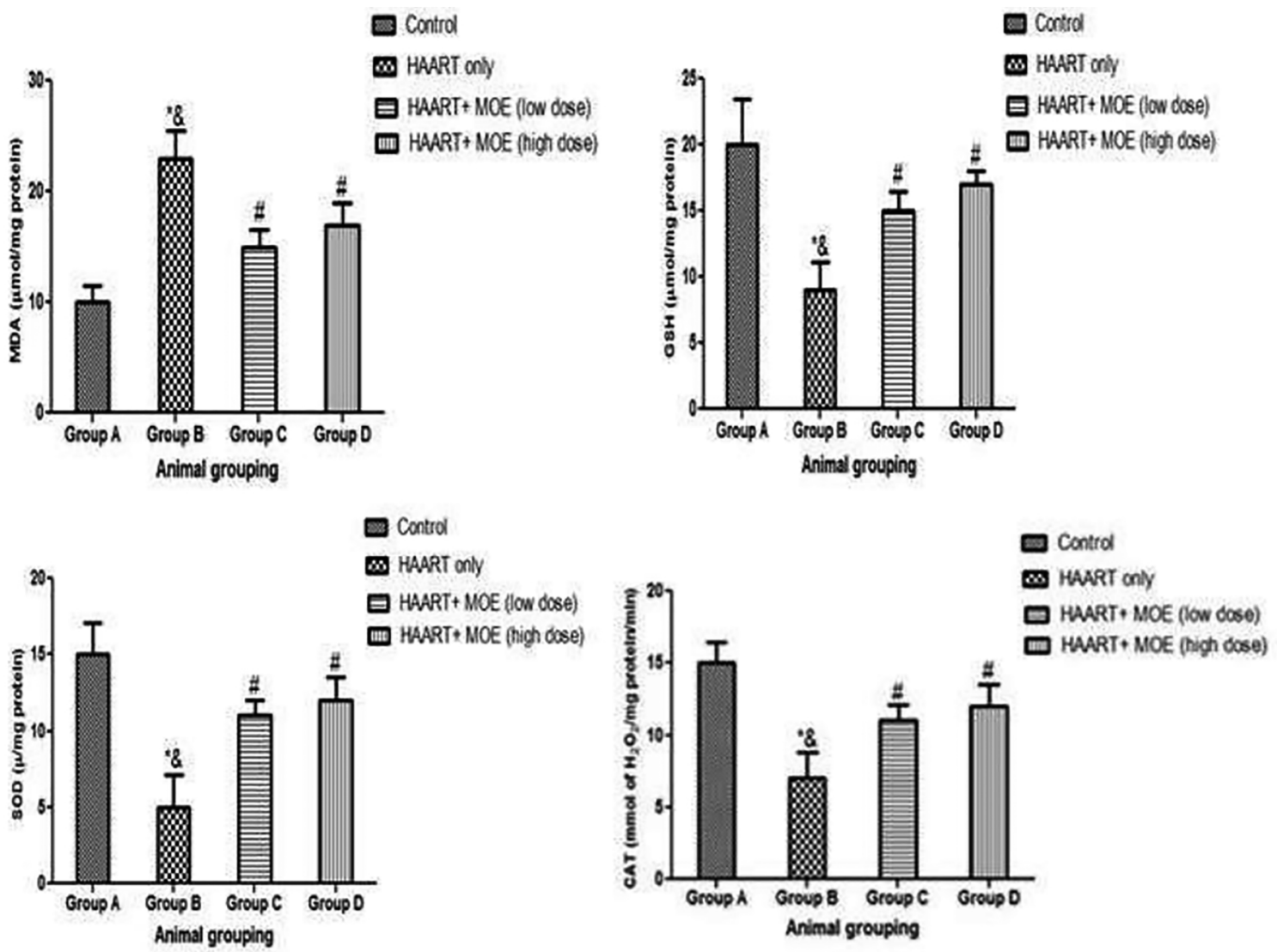

Figure 5. Effect of MOE on MDA, GSH, SOD, and CAT levels on HAART induced normal and experimental rats. $* p<0.05$ as compared to group $\mathrm{A} ; \& p<0.05$ as compared to group $\mathrm{C}$ and $\mathrm{D} ; \# \mathrm{p}<0.05$ as compared to groups $\mathrm{A}$.
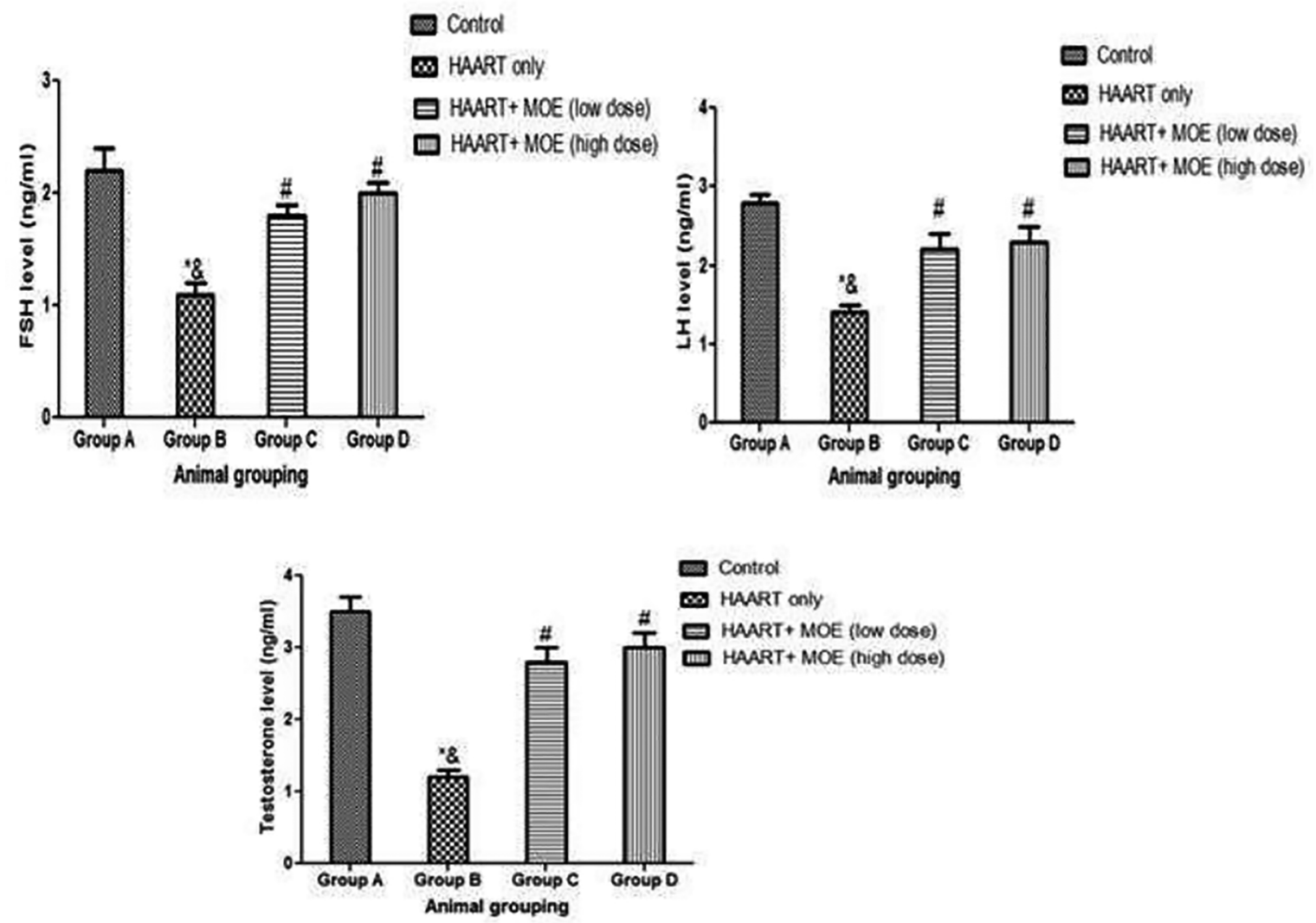

Figure 6. Effect of MOE on serum level of FSH, LH and TT on HAART-induced normal and experimental rats. $* p<0.05$ as compared to group $A ; \& p<0.05$ as compared to group $C$ and $D ; \# p<0.05$ as compared to group $A$. 

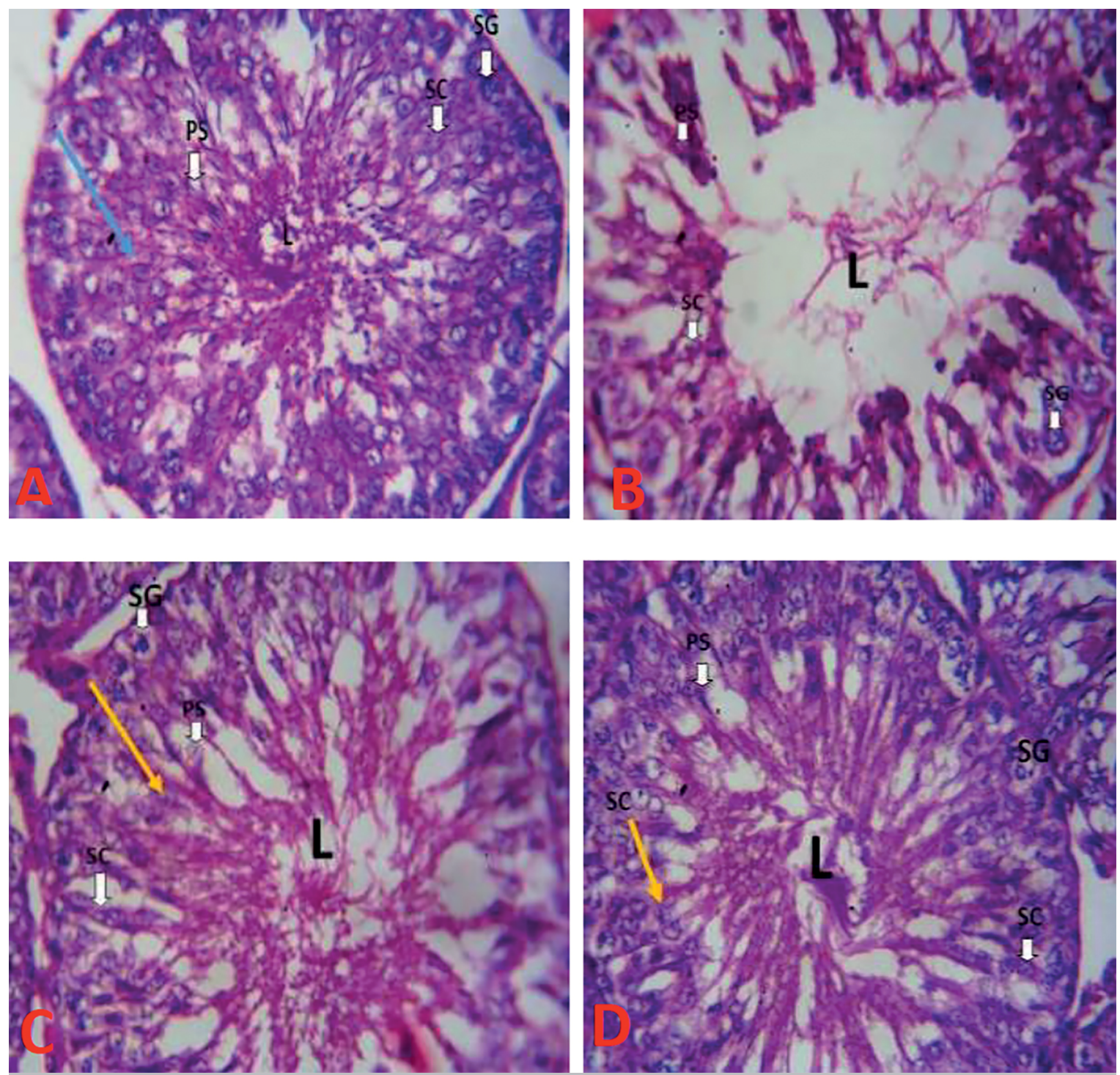

Figure 7. Testicular Photomicrographs showing the effects of MOE on HAART induced normal and experimental rats. Scale bar: $250 \mu \mathrm{m}$. Stains: Hematoxylin and Eosin, Magnification X400.

A: Group A showing testicular photomicrograph section of control rat with normal histoarchitecture of typically organized layers of Sertoli cells (arrow), no pathological changes in the lumen $(L)$ of the seminiferous tubules, with prominent spermatogonia (SG), Primary spermatocyte (PS).

B: Group B showing testicular photomicrograph section of HAART only group with distortion in the tubular architecture and disorganization of the Sertoli cells within the seminiferous tubules, hypocellularity of spermatogonia, disruption of spermatogenesis and empty lumen (L).

C: Group C showing testicular photomicrograph section of MOE and HAART treated group at low dose with visible restored lumen (L), spermatogonia (SG), Primary spermatid (PS) and abundant Sertoli cell (yellow arrow).

D: Group D showing testicular photomicrograph section of MOE and HAART treated group at high dose showing visible lumen (L), spermatogonia (SG), Primary spermatid (PS) and abundant Sertoli cell (yellow arrow).

prediction of chemical toxicity (Asagba et al., 2007). The significant decrease in the weight coefficient of testicular tissue and final body weight in HAART-only treated animals (Group B) compared to controls further corroborate HAART toxicity. Gonadotoxicity occurs through organ swelling, atrophy, or hypertrophy (Afolayan \& Yakubu, 2009). The final body and testicular weights observed in this study corroborated the report by Azu (2012) that revealed that HAART exposure in rats causes shrinkage of the nuclear size of testicular cells and declines in body weight. However, the combination treatment of HAART and MOE at low and high doses (groups $C$ and $D$ respectively), preserves the body and testicular weights associated with HAART toxicity in a dose-dependent manner, thereby mopping up excessive free radicals associated with organ atrophy, which could be attributed to the powerful phytonutrients present within the plants responsible for the preservation of the body and testicular weights, such as vitamins C, E, A; kaempferol, quercetin, rutin (Siddhuraju \& Becker, 2003; Aslam et al., 2005; Kamalakkannan \& Prince, 2006; Al-Malki \& El Rabey, 2015).

The sperm morphology in HAART-treated animals showed a significant defect in the neck and tail regions. This finding conforms to the report by Nicopoullos et al. 
(2010) that showed testicular morphological derangement as a potential target for HAART, thereby revealing that HAART rather than HIV-1, was responsible for the topographic changes in sperm cells. However, the combined administration of HAART and MOE at low and high doses ameliorates the toxicity brought about by HAART exposure in a dose-dependent mechanism.

Furthermore, our study found a significant decrease in the progressive assessment (slow movement), decreased sperm motility, decrease in semen volume, and decrease in total sperm count in HAART-treated animals. Our findings are following previous reports that HIV-1 infection and/or treatment with HAART creates distortions in semen volume and cellular composition (Sertoli or spermatogenic cells), decreased sperm motility, decrease in rapidly progressive motile spermatozoa movement, and decrease in sperm concentration, total count and progressive motility (Azu et al., 2014). However, treatment with MOE at low and high doses mitigated the toxicity brought on by HAART exposure in the semen parameters in a dose-dependent manner; thereby suggesting the antioxidant and protective role of MOE against chemical toxicants. The ameliorative potential exhibited by MOE could be attributed to the radical scavenging activities and the distinct and significant diversity of phytochemicals reacting uniquely with various free radicals (Kim et al., 2003). Previous studies revealed that MOE possesses significant antioxidant activities attributed to a variety of compounds such as anthocyanins and reductones (Custódio et al., 2013).

Furthermore, there was a significant increase in MDA levels, with a concomitant decrease in GSH, CAT, and SOD activities in HAART-treated animals, hence, proving that the testicular tissue of the untreated rats is greatly affected by ROS due to chemically-induced oxidative stress. Our study supports previous findings that revealed an increase in testicular MDA levels after the administration of HAART drugs (Oputiri \& Elias, 2014; Adaramoye et al., 2015). Additionally, the previous study revealed that HAART significantly reduced testicular GSH, SOD, and CAT, consequently reducing antioxidant availability; thereby increasing free radical activity and disrupting the redox balance (Ogedengbe et al., 2018). It has also been reported that an imbalance in redox activity, due to oxidative stress, is highly deleterious to tissue functionality (Rahman et al., 2012; Oyeyipo et al., 2018). However, co-treatment of HAART with MOLE at low and high doses significantly restored lipid peroxidation and raised the levels of GSH, CAT, and SOD in a dose-dependent mechanism, thereby revealing the potential of MOE acting as an antioxidant in mopping up free radicals and ROS after chemical insults. Additionally, the observed restoration of the antioxidant markers could be attributed to the abundant polyphenols present in $\mathrm{MOE}$, which have the electron donor potency capable of detoxifying lipid peroxidation and antioxidant enzyme activation (Jaiswal et al., 2009; Alvarez-Suarez et al., 2011; Oboh et al., 2020).

Also, a significant decrease in $\mathrm{FSH}, \mathrm{LH}$ and $\mathrm{TT}$ levels in HAART treated animals was recorded, which agrees with previous studies that showed that HAART causes deterioration in the functionality of the Sertoli and Leydig cells, weakening spermatogenesis due to decreased FSH, LH, and TT levels (Kiyanifard et al., 2010; Rahman et al., 2012; Ogedengbe et al., 2018). However, co-administration of HAART and MOE at low and high doses restored the hormone profiles by elevating the $\mathrm{FSH}, \mathrm{LH}$, and TT levels in a dose-dependent mechanism; thereby maintaining the physiological function of the testis. Hormonal assessments are an important factor in testicular homeostasis involving the gonadotropin-releasing hormone from the hypothalamus, follicle-stimulating hormone; and luteinizing hormone. The previous report deduced that both luteinizing hormone and follicle-stimulating hormone are necessary for spermatogenesis (Ogedengbe et al., 2018), while follicle-stimulating hormone (FSH) is regarded as a biological marker for accessing Sertoli cell functionality in the spermatogenic process (Ogedengbe et al., 2018). Furthermore, histopathological features revealed significant degeneration of spermatogenic cells with thinning and disorganization of the basement membrane, widened lumen, and hypocellular interstitium observed in the HAART- only group (Group B), compared with the control. This result conforms to previous studies that revealed HAART capability in compromising the morphological integrity of the testicular epithelium and blood-testis barrier of the Sertoli cells (Vasilaki \& McMillan, 2011; Ogedengbe et al., 2018). However, these structural changes were mitigated after the administration of MOE at low and high doses, thereby restoring the lumen of the seminiferous tubules with visible spermatozoa and abundant sperm cells. Previous assessment of MOE showed that the polyphenolic compounds and various antioxidant activities are responsible for the positive restoration of testicular histomorphology, indicating that polyphenols may be due to their hydroxyl groups, thereby serving as major contributors to the free radical scavenging ability of the extracts (Chew et al., 2009).

\section{CONCLUSION}

This study ascribed that HAART reduced body and testicular weights, caused changes to hormone profiles, oxidative stress parameters, and distinctive distortion of the testicular morphology and disorganization of the spermatogenic cells. However, Moringa oleifera leaves had a protective response against HAART toxicity, attributed to the presence of potent phytochemical compounds (such as kaempferol, quercetin, niazimicin, and benzyl isothiocyanate) capable of preserving testicular morphology and functions.

\section{ACKNOWLEDGEMENTS}

The authors are grateful to Dr. Ijomone, FUTA, Akure, and Mr. Ige, OAU, Ife, Nigeria for technical support.

\section{CONFLICT OF INTERESTS}

The authors declare no conflicts of interest.

\section{Correspondence author:}

B. Ogunlade

Human Anatomy Department

Federal University of Technology Akure

Ondo State. Nigeria

E-mail: bogunlade@futa.edu.ng

\section{REFERENCES}

Adaramoye OA, Akanni OO, Adewumi OM, Owumi SE. Lopinavir/Ritonavir, an Antiretroviral Drug, Lowers Sperm Quality and Induces Testicular Oxidative Damage in Rats. Tokai J Exp Clin Med. 2015;40:51-7. PMID: 26150184

Adegoke OO. Transcriptional and Post-Transcriptional Regulation in Testicular Toxicity [Thesis]. Leicester: Medical Research Council Toxicology Unit, University of Leicester; 2015. Available at: https://hdl.handle.net/2381/31979

Adelakun SA, Ukwenya VO, Ogunlade BS, A J Aniah, G A Ibiayo. Nitrite-induced testicular toxicity in rats: therapeutic potential of walnut oil. JBRA Assist Reprod. 2019;23:1523. PMID: 30106544 DOI: $10.5935 / 1518-0557.20180062$ 
Afolayan AJ, Yakubu MT. Effect of Bulbine natalensis Baker stem extract on the functional indices and histology of the liver and kidney of male Wistar rats. J Med Food. 2009;12:814-20. PMID: 19735182 DOI: 10.1089/ jmf.2008.0221

Al-Malki AL, El Rabey HA. The antidiabetic effect of low doses of Moringa oleifera Lam. seeds on streptozotocin induced diabetes and diabetic nephropathy in male rats. Biomed Res Int. 2015;2015:381040. PMID: 25629046 DOI: $10.1155 / 2015 / 381040$

Alvarez-Suarez JM, Dekanski D, Ristić S, Radonjić NV, Petronijević ND, Giampieri F, Astolfi P, González-Paramás AM, Santos-Buelga C, Tulipani S, Quiles JL, Mezzetti B, Battino M. Strawberry polyphenols attenuate ethanol-induced gastric lesions in rats by activation of antioxidant enzymes and attenuation of MDA increase. PLoS One. 2011;6:e25878. PMID: 22016781 DOI: $10.1371 /$ journal.pone.0025878

Anwar F, Latif S, Ashraf M, Gilani AH. Moringa oleifera: a food plant with multiple medicinal uses. Phytother Res. 2007;21:17-25. PMID: 17089328 DOI: 10.1002/ptr.2023

Asagba SO, Adaikpoh MA, Kadiri $\mathrm{H}$, Obi FO. Influence of aqueous extract of Hibiscus sabdariffa L. petal on cadmium toxicity in rats. Biol Trace Elem Res. 2007;115:47-57. PMID: 17406073 DOI: 10.1385/BTER:115:1:47

Aslam M, Anwar F, Nadeem R, Rashid U, Kazi TG, Nadeem M. Mineral Composition of Moringa oleifera Leaves and Pods from Different Regions of Punjab, Pakistan. Asian J Plant Sci. 2005;4:417-21. DOI: 10.3923/ajps.2005.417.421

Azu OO. Highly active antiretroviral therapy (HAART) and testicular morphology: current status and a case for a stereologic approach. J Androl. 2012;33:1130-42. PMID: 22700761 DOI: $10.2164 /$ jandrol.112.016758

Azu OO, Naidu EC, Naidu JS, Masia T, Nzemande NF, Chuturgoon A, Singh S. Testicular histomorphologic and stereological alterations following short-term treatment with highly active antiretroviral drugs (HAART) in an experimental animal model. Andrology. 2014;2:772-9. PMID: 24919589 DOI: 10.1111/j.2047-2927.2014.00233.x

Azu OO, Jegede AI, Ugochukwu O, Onanuga IO, Kharwa S, Naidu EC. Hepatic histomorphological and biochemical changes following highly active antiretroviral therapy in an experimental animal model: Does Hypoxis hemerocallidea exacerbate hepatic injury? Toxicol Rep. 2016;3:114-222. PMID: 28959529 DOI: 10.1016/j.toxrep.2015.12.013

Bujan L, Sergerie M, Moinard N, Martinet S, Porte L, Massip $P$, Pasquier C, Daudin M. Decreased semen volume and spermatozoa motility in HIV-1-infected patients under antiretroviral treatment. J Androl. 2007;28:444-52. PMID: 17215546 DOI: $10.2164 /$ jandrol.106.001529

Carr A, Cooper DA. Adverse effects of antiretroviral therapy. Lancet. 2000;356:1423-30. PMID: 11052597 DOI: $10.1016 / \mathrm{S} 0140-6736(00) 02854-3$

Chew YL, Goh JK, Lim YY. Assessment of in vitro antioxidant capacity and polyphenolic composition of selected medicinal herbs from Leguminosae family in Peninsular Malaysia. Food Chem. 2009;116:13-8. DOI: 10.1016/j. foodchem.2009.01.091
Chris-Ozoko LE, Charity AA, Ekundina VO. Histomorphological Effect of Zidovudine on the Testes of Adult Male WisCarr A, Cooper DA. Adverse effects of antiretroviral therapy. Lancet. 2000;356:1423-30. DOI: 10.1016/ S0140-6736(00)02854-3

Creasy DM. Pathogenesis of male reproductive toxicity. Toxicol Pathol. 2001;29:64-76. PMID: 11215686 DOI: $10.1080 / 019262301301418865$

Custódio L, Patarra J, Alberício F, Neng NR, Nogueira JM, Romano A. Extracts from Quercus sp. acorns exhibit in vitro neuroprotective features through inhibition of cholinesterase and protection of the human dopaminergic cell line SH-SY5Y from hydrogen peroxide-induced cytotoxicity. Ind Crops Prod. 2013;45:114-20. DOI: 10.1016/j.indcrop.2012.12.011

Ellman GL. Tissue sulfhydryl groups. Arch Biochem Biophys. 1959;82:70-7. PMID: 13650640 DOI: 10.1016/00039861(59)90090-6

Granich R, Crowley S, Vitoria M, Smyth C, Kahn JG, Bennett R, Lo YR, Souteyrand Y, Williams B. Highly active antiretroviral treatment as prevention of HIV transmission: review of scientific evidence and update. Curr Opin HIV AIDS. 2010;5:298304. PMID: 20543604 DOI: $10.1097 / \mathrm{COH} .0 b 013$ e32833a6c32

Hagmann M. Study confirms effectiveness of antiretroviral drugs for HIV patients. Bull World Health Organ. 2003;81:918-9. PMID: 14997251

Hamza AA. Ameliorative effects of Moringa oleifera Lam seed extract on liver fibrosis in rats. Food Chem Toxicol. 2010;48:345-55. PMID: 19854235 DOI: $10.1016 / \mathrm{j}$. fct.2009.10.022

Hermawan A, Nur KA, Sarmoko, Dewi D, Putri DD, Meiyanto E. Ethanolic Extract of Moringa oleifera Increased Cytotoxic Effect of Doxorubicin on HeLa Cancer Cells. J Nat Remedies. 2012;12:108-14.

Huang GJ, Deng JS, Huang SS, Shao YY, Chen CC, Kuo $\mathrm{YH}$. Protective effect of antrosterol from Antrodia camphorata submerged whole broth against carbon tetrachloride-induced acute liver injury in mice. Food Chem. 2012;132:709-16. DOI: 10.1016/j.foodchem.2011.11.004

Jaiswal D, Kumar Rai P, Kumar A, Mehta S, Watal G. Effect of Moringa oleifera Lam. leaves aqueous extract therapy on hyperglycemic rats. J Ethnopharmacol. 2009;123:392-6. PMID: 19501271 DOI: 10.1016/j.jep.2009.03.036

Kamalakkannan N, Prince PS. Antihyperglycaemic and antioxidant effect of rutin, a polyphenolic flavonoid, in streptozotocin-induced diabetic wistar rats. Basic Clin Pharmacol Toxicol. 2006;98:97-103. PMID: 16433898 DOI: 10.1111/j.1742-7843.2006.pto_241.x

Kim DO, Chun OK, Kim YJ, Moon HY, Lee CY. Quantification of polyphenolics and their antioxidant capacity in fresh plums. J Agric Food Chem. 2003;51:6509-15. PMID: 14558771 DOI: $10.1021 /$ jf0343074

Kiyanifard D, Hassanzadeh SH, Sadrkhanlo RA, Farshid A. Study of changes structure seminiferous tubule and hormone changes gonadotropin diabetic rats. Med J Med. $2010 ; 22: 239-48$. 
Kushnir VA, Lewis W. Human immunodeficiency virus/ acquired immunodeficiency syndrome and infertility: emerging problems in the era of highly active antiretrovirals. Fertil Steril. 2011;96:546-53. PMID: 21722892 DOI: $10.1016 /$ j.fertnstert.2011.05.094

Lai TY, Weng YJ, Kuo WW, Chen LM, Chung YT, Lin YM, Tsai FJ, Lee CH, Choong YM, Lai EY, Huang CY, Yeh YL. Taohe Chengqi Tang ameliorates acute liver injury induced by carbon tetrachloride in rats. Zhong Xi Yi Jie He Xue Bao. 2010;8:49-55. PMID: 20082759 DOI: 10.3736/jcim20100110

Mahmood KT, Mugal, Haq IU. Moringa oleifera: a natural gift - A review. J Pharm Sci Res. 2010;2:775-81.

Marklund S, Marklund G. Involvement of the superoxide anion radical in the autoxidation of pyrogallol and a convenient assay for superoxide dismutase. Eur J Biochem. 1974;47:469-74. PMID: 4215654 DOI: $10.1111 / j .1432-$ 1033.1974.tb03714.x

Meynard JL, Morand-Joubert L, Chêne G, Landman R, Pinta A, Kraemer S, Obadia M, Girard PM. Two-Year Observational Study in Patients Infected with Drug-Resistant HIV-1 and Treated with the Fusion Inhibitor Enfuvirtide: The ZOOM Cohort. J AIDS Clin Res. 2011;2:114. DOI: 10.4172/2155-6113.1000114

Mishra G, Singh P, Verma R, Kumar S, Srivastav S, Jha KK, Khosa RL. Traditional uses, phytochemistry and pharmacological properties of Moringa oleifera plant: An overview. Pharm Lett. 2011;3:141-64.

Montessori V, Press N, Harris M, Akagi L, Montaner JS. Adverse effects of antiretroviral therapy for HIV infection. CMAJ. 2004;170:229-38. PMID: 14734438

Nakamura Y, Kawakami M, Yoshihiro A, Miyoshi N, Ohigashi $H$, Kawai $K$, Osawa $T$, Uchida $K$. Involvement of the mitochondrial death pathway in chemopreventive benzyl isothiocyanate-induced apoptosis. J Biol Chem. 2002;277:8492-9. PMID: 11751909 DOI: 10.1074/jbc. M109760200

Nicopoullos JD, Almeida P, Vourliotis M, Goulding R, GillingSmith C. A decade of sperm washing: clinical correlates of successful insemination outcome. Hum Reprod. 2010;25:186976. PMID: 20534606 DOI: 10.1093/humrep/deq134

Niehaus WG Jr, Samuelsson B. Formation of malonaldehyde from phospholipid arachidonate during microsomal lipid peroxidation. Eur J Biochem. 1968;6:126-30. PMID: 4387188 DOI: $10.1111 /$ j.1432-1033.1968.tb00428.x

Oboh G, Ogunbadejo MD, Ogunsuyi OB, Oyeleye SI. Can gallic acid potentiate the antihyperglycemic effect of acarbose and metformin? Evidence from streptozotocin-induced diabetic rat model. Arch Physiol Biochem. 2020:1-9. Epub ahead of print. PMID: 31979987 DOI: $10.1080 / 13813455.2020 .1716014$

Ogedengbe OO, Naidu EC, Akang EN, Offor U, Onanuga IO, Peter AI, Jegede AI, Azu OO. Virgin coconut oil extract mitigates testicular-induced toxicity of alcohol use in antiretroviral therapy. Andrology. 2018;6:616-26. PMID: 29654715 DOI: $10.1111 /$ andr. 12490
Oputiri D, Elias A. Impact of co-administered Lopinavir/ Ritonavir and Sulfamethoxazole/Trimethoprim on Reproductive Indices of Male Albino Rats. Am J Pharmacol Sci. 2014;2:93-9. DOI: 10.12691/ajps-2-5-4

Oyeyipo IP, Skosana BT, Everson FP, Strijdom H, du Plessis SS. Highly Active Antiretroviral Therapy Alters Sperm Parameters and Testicular Antioxidant Status in Diet-Induced Obese Rats. Toxicol Res. 2018;34:41-8. PMID: 29372000 DOI: $10.5487 / T R .2018 .34 .1 .041$

Paliwal R, Sharma V, Pracheta, Sadhna S. Elucidation of free radical scavenging and antioxidant activity of aqueous and hydro-ethanolic extract of Moringa oleifera pods. Res J Pharm Techol. 2011;4:566-71.

Pineda JA, Alcamí J, Blanco JR, Blanco J, Boix V, Casado JL, De Quirós JC, Llibre JM. Hot Immunological Topics in HIV Infection. J AIDS Clinic Res. 2011;2:118. DOI: 10.4172/2155-6113.1000118

Rahman T, Hosen I, Islam MM, Shekhar HU. Oxidative stress and human health. Adv Biosci Biotechnol. 2012;3:9971019. DOI: $10.4236 / a b b .2012 .327123$

Reginald OO, Mohammed MH, Olayinka AT, Sani GB, Tobi-Ajayi E, Aliyu IS, Mathew I, Chigozie I, Bilkisu U, Ibrahim AA. Hematological and Metabolic Toxicities of Current Antiretroviral Regimens in Ahmadu Bello University Teaching Hospital Shika Zaria, Northern Nigeria. J AIDS Clinic Res. 2011;S2:002. DOI: 10.4172/2155-6113.S2-002

Saalu LC, Akunna GG, Ajayi GO. Modulating Role of Bitter Leaf on Spermatogenic and Steroidogenesis Functions of the Rat Testis. Am J Biochem Mol Biol. 2013;3:314-21. DOI: $10.3923 / a j b m b .2013 .314 .321$

Sharma V, Paliwal R, Janmeda P, Sharma S. Renoprotective effects of Moringa oleifera pods in 7,12-dimethylbenz [a] anthracene-exposed mice. Zhong Xi Yi Jie He Xue Bao. 2012;10:11718. PMID: 23073202 DOI: $10.3736 /$ jcim20121015

Siddhuraju P, Becker K. Antioxidant properties of various solvent extracts of total phenolic constituents from three different agroclimatic origins of drumstick tree (Moringa oleifera Lam.) leaves. J Agric Food Chem. 2003;51:214455. PMID: 12670148 DOI: $10.1021 /$ jf020444+

Singh GP, Sharma SK. Antimicrobial evaluation of leaf extract of Moringa oleifera Lam. Int Res J Pharm. 2012;3:212-5.

Sinha AK. Colorimetric assay of catalase. Anal Biochem. 1972;47:389-94. PMID: 4556490 DOI: 10.1016/00032697(72)90132-7

Vasilaki AT, McMillan DC. Lipid Peroxidation. In: Schwab M, ed. Encyclopedia of Cancer. Berlin, Heidelberg: Springer; 2011. p. 2054-5.

Villarruel-López A, López-de la Mora DA, Vázquez-Paulino OD, Puebla-Mora AG, Torres-Vitela MR, Guerrero-Quiroz LA, Nuño K. Effect of Moringa oleifera consumption on diabetic rats. BMC Complement Altern Med. 2018;18:127. PMID: 29636032 DOI: 10.1186/s12906-018-2180-2 